\title{
Intestinal lipid-derived signals that sense dietary fat
}

\author{
Nicholas V. DiPatrizio' and Daniele Piomelli, ${ }^{1,2,3,4}$ \\ 'Departments of Anatomy and Neurobiology, ${ }^{2}$ Department of Pharmacology, and ${ }^{3}$ Department of Biological Chemistry, School of Medicine, University of California, Irvine, Irvine, California, USA. \\ ${ }^{4}$ Drug Discovery and Development, Istituto Italiano di Tecnologia, Genoa, Italy.

\begin{abstract}
Fat is a vital macronutrient, and its intake is closely monitored by an array of molecular sensors distributed throughout the alimentary canal. In the mouth, dietary fat constituents such as mono- and diunsaturated fatty acids give rise to taste signals that stimulate food intake, in part by enhancing the production of lipid-derived endocannabinoid messengers in the gut. As fat-containing chyme enters the small intestine, it causes the formation of anorexic lipid mediators, such as oleoylethanolamide, which promote satiety. These anatomically and functionally distinct responses may contribute to the homeostatic control and, possibly, the pathological dysregulation of food intake.
\end{abstract}

\section{Introduction}

Dietary fat occupies a central place in the complex molecular web that controls energy homeostasis in animals $(1,2)$. Its fatty acid constituents are not only highly caloric - they pack more than twice the energy than do carbohydrates or proteins - but are also necessary to build cellular membranes and produce essential lipid-derived mediators such as prostaglandins, leukotrienes, and endocannabinoids (3). It is not surprising, therefore, that chemosensory and neural mechanisms have been selected for during evolution to closely monitor fat intake and optimize the seeking, sensing, and storage of this vital macronutrient $(2,4,5)$. Indeed, the sharp seasonal and geographic fluctuations in availability of fat-rich foods, which are typical of natural environments and archaic human societies (6), are a likely source of the selective pressure that endowed these fatsensing mechanisms with unusual saliency $(7,8)$. Our species' hard-wired attraction to fat has lost much of its adaptive value in contemporary societies, where fatty foods are easily and continually available, and may contribute to the growing prevalence of overweight and obesity $(2,9)$.

An interacting network of peripheral and central circuits, which have been only partially mapped, governs the intake of palatable fat-containing foods: peripheral signals such as cholecystokinin and leptin (10), along with central neurotransmitters such as opioid peptides (8) and melanin-concentrating hormone (11), are known to be involved. The focus of this Review is on two classes of lipid-derived mediators produced in the gut that have recently emerged as important fat-dependent regulators of hunger and satiety. These are esters of long-chain unsaturated fatty acids (LCUFAs) with glycerol, such as 2-arachidonoyl-snglycerol (2-AG) and 2-oleoyl-sn-glycerol (2-OG), and amides of LCUFA with ethanolamine, such as arachidonoylethanolamide (anandamide) and oleoylethanolamide (OEA) (Figure 1).

Conflict of interest: Daniele Piomelli is a cofounder of Thesan Pharmaceuticals and Anteana Therapeutics, two biopharmaceutical companies dedicated to the development of innovative therapies for skin diseases and pain, respectively. Daniele Piomelli owns equity in both companies.

Reference information: / Clin Invest. 2015;125(3):891-898. doi:10.1172/JCI76302.
Despite their structural similarities, these substances interact with distinct molecular targets and elicit widely different biological responses.

Anandamide and 2-AG are high-affinity agonists for the $G$ protein-coupled cannabinoid receptors $\mathrm{CB}_{1}$ and $\mathrm{CB}_{2}$ (12). Activation of the $\mathrm{CB}_{1}$ receptor subtype - which is particularly abundant in the brain and spinal cord, but is also spread throughout the rest of the body (13) - increases food intake, enhances reward aspects of eating, and promotes energy conservation $(4,14)$. Conversely, pharmacological or genetic blockade of the receptor decreases feeding, sustains weight loss, heightens insulin sensitivity, and improves dysregulated lipid metabolism in both animal models and obese humans $(14,15)$. Central and peripheral mechanisms cooperate to produce these effects. Evidence for a central component includes, for example, the finding that microinjections of anandamide into hedonic "hot spots" in the rat nucleus accumbens enhance affective orofacial ("liking") reactions (16) to a pleasant food taste (sucrose) (17) and, conversely, that genetic deletion of $\mathrm{CB}_{1}$ receptors or of the 2-AG-deactivating enzyme monoacylglycerol lipase in mouse forebrain neurons causes leanness, accrued thermogenesis, and resistance to diet-induced obesity $(18,19)$. Important sites of endocannabinoid action outside the brain are the liver and the adipose organ, where $C_{1}$ receptors act as positive regulators of lipogenesis (20), as well as the small intestine, where their activation slows down peristalsis $(21,22)$, suppresses mucosal inflammation (23), and increases food intake $(24,25)$. In the first two sections of this Review, we outline the molecular and neural pathways underlying fat taste and discuss the possible role of gut endocannabinoids as hunger signals triggered by fat ingestion.

OEA is a nanomolar agonist of PPAR $\alpha$, a member of the nuclear receptor superfamily $(26,27)$. PPAR $\alpha$ is responsible for most of the biological actions of OEA, including its ability to curb food intake $(26,28,29)$, enhance fatty acid absorption in small intestinal enterocytes $(26,30)$, and stimulate lipid usage (lipolysis or oxidation) in adipocytes, hepatocytes, and skeletal myocytes $(31,32)$. In addition to PPAR $\alpha$, OEA activates the GPCR GPR119 (33) and, by doing so, stimulates secretion of the insulin-releasing factor glucagon-like peptide 1 (GLP1) from enteroendocrine L 
Glycerol esters

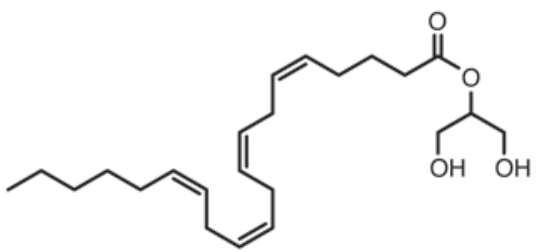

2-AG

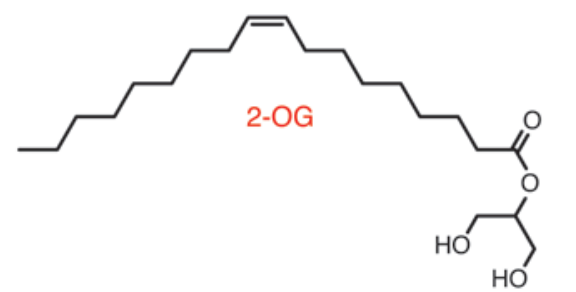

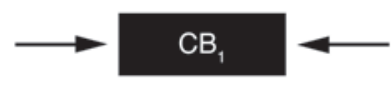

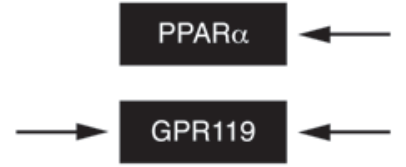

Ethanolamides

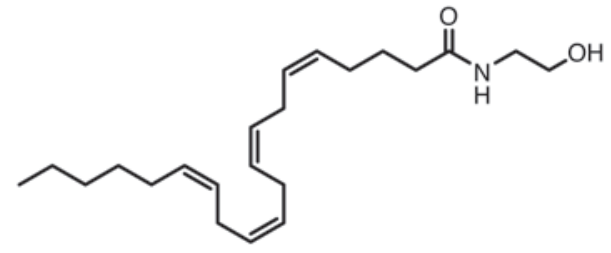

AEA

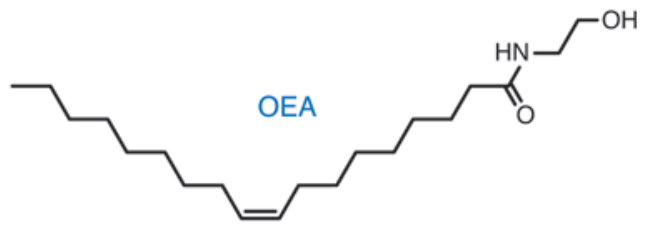

Figure 1. Chemical structures and molecular targets of lipid-derived mediators involved in the monitoring of dietary fat. Left: fatty acyl glycerol esters 2-AG and 2-OG. Right: fatty acyl ethanolamides anandamide (AEA) and OEA. OEA and 2-OG may contribute in complementary ways to the postingestive control of satiety. 2-OC may act as a local regulator of GLP1 release through its ability to activate GPR119 on the apical surface of enteroendocrine $L$ cells of the ileum. It is likely to reach millimolar concentrations in the lumen of the upper gut during fat digestion. OEA is produced by duodenal and jejunal enterocytes and modifies meal patterns in a manner similar to a satiety signal, increasing the time between meals. This activity is dependent on OEA binding of PPAR $\alpha$. OEA also engages GPR119 to drive secretion of GLP1 (27). Anandamide and 2-AC are high-affinity agonists for the GPCR cannabinoid receptors $\mathrm{CB}_{1}$ and $\mathrm{CB}_{2}$. Activation of $\mathrm{CB}_{1}$ increases food intake, enhances reward aspects of eating, and promotes energy conservation (4).

cells of the ileum $(34,35)$. The glycerol ester analog of OEA, 2-OG (Figure 1), also interacts with GPR119, albeit less potently and effectively than does OEA (36).

When chyme transits through the upper intestine, the absorptive epithelium lining the gut wall captures oleic acid liberated by the digestion of dietary triacylglycerols and converts it into OEA (37). This "nutrient-turned-mediator" prolongs the interval between successive meals, i.e., it enhances satiety $(37,38)$, via a mechanism that is still unclear but requires both PPAR $\alpha$ activation and recruitment of capsaicin-sensitive afferent fibers $(28,37)$. The OEA precursor, $N$-oleoyl-phosphatidylethanolamine (NOPE), and other $N$-acylated PE derivatives are also generated by the arrival of fat-containing chyme in the upper gut and may exert effects that are functionally similar but mechanistically distinct from those of OEA (39). In the last two sections of this article, we discuss evidence suggesting that OEA may act as a postingestive "stop" signal for dietary fat intake, and propose an integrated view of how this anorexic lipid-derived mediator might cooperate with orexigenic endocannabinoid-mediated signaling to modulate the ingestion of dietary fat (Figure 2).

\section{Fat taste}

Unlike obligatory herbivores and carnivores, which have inherently narrow boundaries of food choice, humans and other omnivores fulfill their energy requirements by consuming calories from a diversity of plant and animal sources $(40,41)$. This nutritional flexibility, which gives omnivores the distinctive capability of adapting their nutrient sources to seasonal and geographical changes in flora and fauna, has important evolutionary conse- quences. For example, net diversification rates (the cumulative effect of speciation and extinction) are lower for omnivorous species than they are for herbivores and carnivores (42). While omnivory offers greater resistance to evolutionary pressures and adaptability in the face of shifting environmental forces (43), it also exacerbates the need to make frequent and complex dietary choices that are critical to the well-being of an animal. This unique decision-making task requires the integration of competing (Pavlovian, habitual, and goal-directed) behavioral controllers working in unison with homeostatic regulators such as ghrelin and leptin (44). Ultimately, however, dietary selection depends on the animal's ability to monitor specific nutrient classes present in the diet and reliably gauge their intake against the changing needs of the organism. The chemical senses, smell and taste, as well as chemosensory responses to texture are all to varying degrees involved in the perception of fat $(45,46)$. However, studies in humans $(47)$ and rodents $(48,49)$ have demonstrated that smell is not critical for fat detection, whereas taste is irreplaceable.

Foods are sensed in the oral cavity by receptors present on the surface of taste bud cells, which transduce chemical signals generated during feeding into electrical currents that are carried to the brain by fibers of the cranial nerve VII (CNVII, facial), CNIX (glossopharyngeal), and CNX (vagus)(50). These gustatory messages enter the nucleus of the solitary tract (NST) in the caudal brainstem, where they merge with information coming from the gut via the afferent vagus nerve. Neurotransmission continues onto the parabrachial nucleus of the pons, which communicates in a bidirectional manner with forebrain regions that control food reward and energy homeostasis (4, 51-54). Experiments in rodents have 


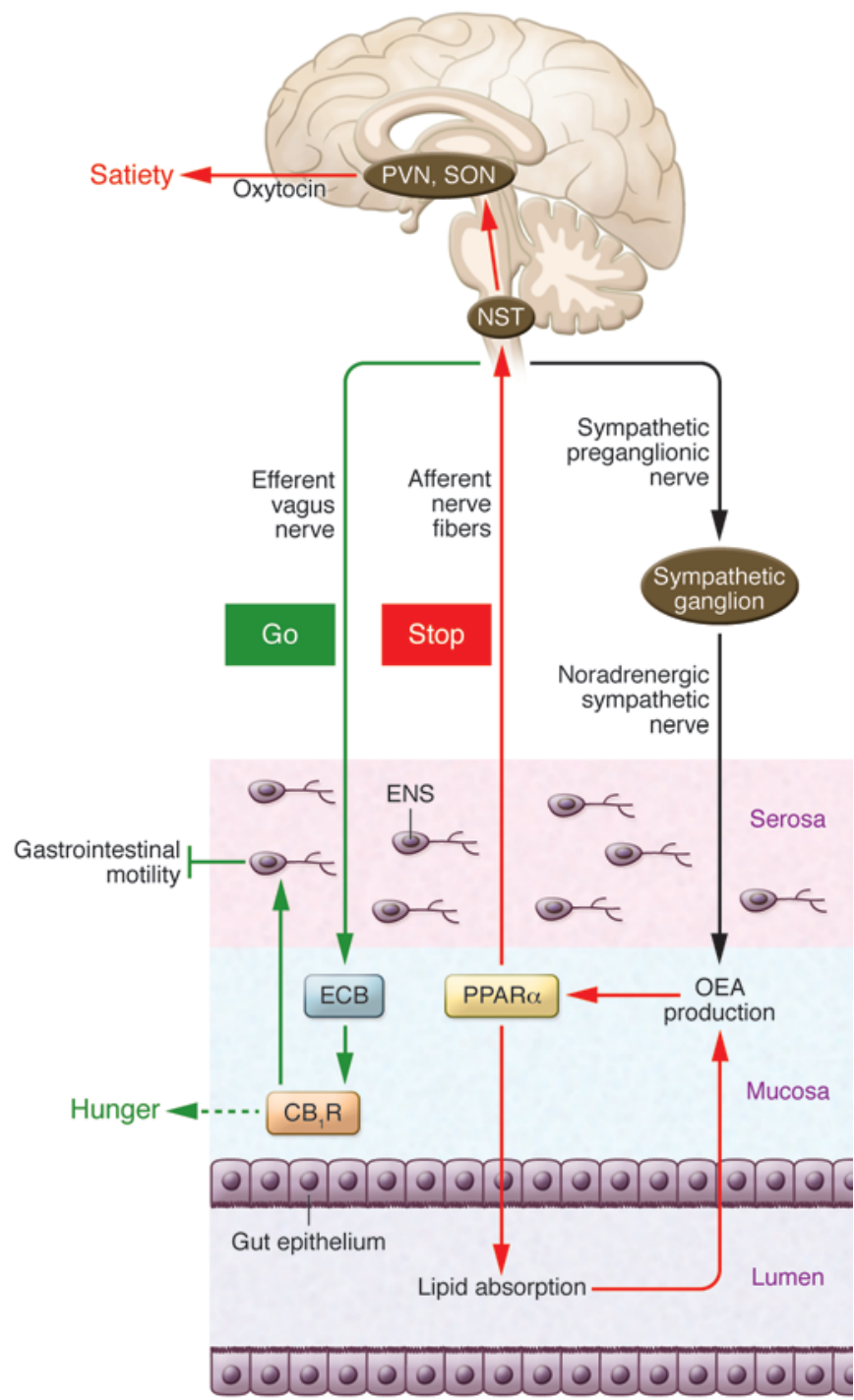

demonstrated the critical role played by gustatory neurotransmission in fat detection and preference. For example, surgical resection of the chorda tympani (branch of CNVII) or CNIX in rodents decreases both intake of and preference for a high-fat liquid meal (55-59). Conversely, oral exposure to fat increases the activity of taste-sensitive neurons of the NST (57) and excites forebrain circuits involved in food reward $(60,61)$.

The exact chemical source of fat taste is still debated (62, 63). Nevertheless, the available data indicate that release of nonesterified fatty acids (FFAs) from triacylglycerols - the main quantitative component of dietary fat - is required to detect this macronutrient in both humans $(64,65)$ and rodents $(66)$. Humans readily distinguish low intraoral concentrations of triacylglycerols (62), and pharmacological inhibition of the enzyme lingual lipase $(67,68)$, which catalyzes the hydrolysis of these composite lipids into individual FFAs, impairs this ability (65). Similar to our species, rodents prefer liquid diets containing triacylglycerols, but this preference disappears when the animals are treated with the lipase inhibitor tetrahydrolipstatin (66). These findings strongly implicate the release of FFAs by oral lipolytic activity as a key determinant of fat taste.
Figure 2. Regulation of fat intake by lipid-derived mediators in the gut. According to this model, oral exposure to fat stimulates endocannabinoid (ECB) mobilization in the jejunum and activation of local $\mathrm{CB}_{1}$ receptors $\left(\mathrm{CB}_{1} \mathrm{Rs}\right)$. This signaling event, which requires the efferent vagus nerve, may act as a "go" signal that promotes further eating $(83,84)$. While the precise mechanism underlying this orexigenic response is unknown, the presence of $\mathrm{CB}_{1} \mathrm{R}$ in cells of the stomach that secrete ghrelin (88) and in enteroendocrine I cells that release cholecystokinin (89) suggests a possible involvement of these peptide hormones. Gut $\mathrm{CB}_{1} \mathrm{Rs}$ also control gastrointestinal motility $(86,87,90,91)$ and mucosal inflammation (23). When fat-containing chyme reaches the upper intestine, it initiates the production of several lipid-derived mediators, including OEA, a process that depends on sympathetic activation of $\beta_{2}$ adrenoreceptors $(37,120)$. OEA stimulation of PPAR $\alpha$ may act as a "stop" signal for feeding by recruiting afferent sensory fibers, possibly of the vagal nerve $(26,28,113)$. The signal is transferred to the NST in the brainstem, from which neurotransmission continues to magnocellular oxytocin-secreting neurons in the paraventricular (PVN) and supraoptic nucleus (SON) of the hypothalamus $(28,116)$, as well as to histaminergic neurons of the tuberomammillary nucleus (118). ENS, enteric nervous system.

There is also convincing evidence that the sensory experience associated with the eating of fatty foods is initiated by gustatory signals that require selective receptors on taste bud cells to be engaged by FFAs $(62,63)$. Deletion of genes encoding four distinct candidate receptors has yielded results that support this conclusion. Mice lacking the multifunctional membrane glycoprotein CD36 the cation-selective transient receptor potential type M5 (TRPM5), or the GPCRs GPR40 and GPR120 all display significant reductions in preference for LCUFAs (69-72). Furthermore, application of LCUFAs elevates intracellular $\mathrm{Ca}^{2+}$ levels in isolated mouse taste cells, an effect that is blunted in cells lacking CD36 (73) or TRPM5 (72). Adding clinical relevance to these findings, a single nucleotide polymorphism in the CD36 gene of obese African-American women has been associated with an increase in the detection threshold for fat (64). In addition, a study in obese men found increased detection threshold for fat compared with lean controls (74). Thus, the information currently available allows us to identify CD36, TRPM5, GPR40, and GPR120 as candidate fattaste receptors. As an evolutionary test of this idea, it would be interesting to determine whether expression of these proteins is conserved in marine mammals that have lost all other taste receptors (e.g., sea lions and whales) $(41,75)$ or terrestrial mammals that are insensitive to the taste of sweet (e.g., obligatory carnivores such as cats) (41) or umami (e.g., highly specialized herbivores such as the panda) (76).

\section{Gut endocannabinoids as hunger signals}

The orosensory qualities of fat are a major contributor to the hedonic properties of this macronutrient (63). For example, rats avidly consume corn oil emulsions even under sham feeding conditions, when postingestive feedbacks are absent (see below) (77). This is due, at least in part, to a direct activation of reward centers in the brain. Microdialysis experiments in shamfeeding rats have shown, indeed, that oral presentation of fat triggers the release of dopamine in the nucleus accumbens (60, $61)$, a critical controller of value learning (78-82). In addition to these central processes, oral fat also deploys multiple regulatory responses in the periphery of the body. For example, building 
on pioneering experiments by the laboratory of Gerard P. Smith (77), Philippe Besnard, and coworkers have demonstrated that lingual application of linoleic acid rapidly elevates pancreatic and biliary secretions in anesthetized mice whose esophagus was clamped to prevent access of the fatty acid to the stomach (69). This finding links the cephalic response to fat to a peripheral physiological event that is probably mediated by efferent vagal neurotransmission.

Another such event may be the activation of endocannabinoid signaling in the upper gut (Figure 2). This idea is supported by studies in which a sham feeding protocol was utilized to test whether tasting carbohydrates, proteins, or fats stimulates endocannabinoid mobilization. In this protocol, a surgical intervention prevented food from accumulating in the stomach and small intestine, allowing the investigation of orosensory feeding controls in the absence of postingestive influences (77). Sham-feeding rats were offered a nutritionally complete liquid diet or liquid meals containing individual macronutrients (corn oil, sucrose, or a protein lysate) (83). After sham feeding, brain and peripheral organs were harvested and their endocannabinoid content was measured by liquid chromatography/mass spectrometry. Oral exposure to corn oil increased the levels of 2-AG and anandamide in the proximal small intestine (jejunum), but not elsewhere in the body, including brain regions involved in the control of food intake or reward (83). Importantly, this effect (a) was nutrient-specific, because sham feeding sugar or protein did not change jejunal endocannabinoid levels; and (b) was not attributable to the texture of corn oil, because mineral oil failed to mimic it (83). In another set of experiments in which rats were sham fed suspensions of pure FFAs, oleic acid (shorthand designation 18:1 $\Delta^{9}$, which denotes a fatty acid with 18 carbon atoms and one cis double bond between

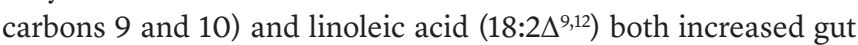
endocannabinoid levels in a manner similar to corn oil, whereas the saturated fatty acid, stearic acid (18:0), or the polyunsaturated fatty acid, linolenic acid $\left(18: 3 \Delta^{9,12,15}\right)$, had no such effect (84). This unexpected structural selectivity reveals an important role for fatty acid composition in the detection of dietary fat and is consistent with the idea that receptor-dependent mechanisms are at play in the oral perception of this nutrient.

To elucidate the neural pathway through which oral exposure to fat drives small intestinal endocannabinoid mobilization, rats were subjected to subdiaphragmatic resection of the vagus nerve, which completely interrupted this major two-way route connecting the brain to the gut (85). The procedure abolished the spike in endocannabinoid levels elicited by fat sham feeding (83), suggesting that the presence of fat in the mouth stimulates gut endocannabinoid signaling by engaging efferent vagal neurotransmission.

Why are endocannabinoids produced in response to fat taste? And why are they produced in the gut? The fact that fasting exerts an effect similar to oral fat exposure $(24,86)$ points to the possibility that small-intestinal endocannabinoids may act as hunger signals. Consistent with this idea, intraduodenal infusion of the $\mathrm{CB}_{1}$ inverse agonist, rimonabant, or systemic injection of the brain-impermeant neutral $\mathrm{CB}_{1}$ antagonist, URB447, each attenuates sham feeding of corn oil (83). Additionally, peripheral blockade of $\mathrm{CB}_{1}$ receptors suppresses the intake of linoleic acid in a two-bottle choice test conducted on sham-feeding rats. In this test, the animals were shown to strongly prefer linoleic acid, which increases gut endocannabinoid levels over mineral oil, which has no such effect (84).

To sum up, the studies outlined above suggest that small-intestinal endocannabinoid signaling - started by oral exposure to select LCUFAs and transmitted to the gut by the vagus nerve - mediates the orexigenic response caused by the tasting of fatcontaining foods. More work is needed to understand how gut endocannabinoids communicate with the brain. If $\mathrm{CB}_{1}$ receptors on terminals of the vagus nerve are involved, they are probably replaceable because mice in which such receptors have been selectively deleted show no change in food intake or body weight (however, these mice do have altered gut motility) (87). On the other hand, the presence of $\mathrm{CB}_{1}$ receptors in ghrelin cells of the stomach (88) and cholecystokinin-secreting enteroendocrine I cells of the duodenum (89) is suggestive of an indirect action mediated by these gut peptide hormones. In addition to testing this idea, future experiments should also aim at providing a more integrated picture of the physiological functions served by the endocannabinoid system in the gut. In particular, it is important to assess whether the known ability of these lipid mediators to delay peristalsis (86, $87,90,91)$ and attenuate mucosal innate immune responses (23) is part of a broader adaptive strategy aimed at optimizing the absorption of dietary fat, which is slower than the absorption of other nutrients and is accompanied by activation of local mast cells (92). It would be also interesting to examine in greater detail the role of $\mathrm{CB}_{1}$ receptors located on sympathetic nerve terminals, which have been implicated in the anti-obesity effects of the $\mathrm{CB}_{1}$ inverse agonist, rimonabant (93).

\section{Lipid-derived signals of satiety}

Postingestive processes are critical to the control of fat intake (27, 94). This point is well illustrated by experiments showing that the local infusion of fat into the duodenum of humans or rodents exerts potent inhibitory effects on feeding by both enhancing satiation (i.e., reducing meal size) and maintaining satiety (i.e., increasing inter-meal intervals) (27, 77, 95-97). The anorexic effects of intraduodenal fat require afferent vagal fibers $(98,99)$ and are partly due to the release of cholecystokinin from enteroendocrine I cells in the proximal gut $(98,100,101)$. These cells express various cell surface receptors that bind FFAs, including GPR120, TRPM5, and FFA receptors 1-3 (102). Gilbertson and collaborators have shown that polyunsaturated FFAs stimulate STC-1 enteroendocrine cells to secrete cholecystokinin by direct activation of GPR120 and downstream recruitment of TRPM5 (103).

In addition to cholecystokinin, two distinct lipid-derived signaling molecules - 2-OG and OEA (Figure 1) - may contribute in complementary ways to the postingestive control of satiety. The action of pancreatic lipase on dietary triacylglycerols generates 2-OG and other 2-monoacylglycerols. It is likely to reach millimolar concentrations in the lumen of the upper gut during fat digestion and may act as a local regulator of GLP1 release by virtue of its ability to activate GPR119 receptors localized to the apical surface of enteroendocrine L cells of the ileum (104). The administration of exogenous 2-OG through a duodenal catheter increases circulating GLP1 levels in human volunteers (36). It is still unclear, however, whether 2-OG released following the hydrolysis of triacyl- 
glycerols by pancreatic lipase is capable of eliciting a similar effect. Interestingly, a recent study showed that dietary lipids directly induce GLP1 release from taste bud cells, which might contribute to the reinforcing properties of fats (105).

While many questions about 2-OG remain unanswered, a great deal more is known about the formation and physiological implications of OEA (27). Duodenal and jejunal enterocytes produce this bioactive lipid substance in three consecutive steps. They first internalize oleic acid released during fat digestion, through a mechanism that requires the membrane glycoprotein CD36 (37); they then use the newly absorbed fatty acid as substrate for the biosynthesis of NOPE, a member of the $N$-acylphosphatidylethanolamine (NAPE) family of membrane phospholipids, and finally cleave NOPE to generate OEA (37). These reactions are accompanied by accrued activity in the biochemical pathway that generates OEA (26). The long evolutionary history of feeding-dependent OEA mobilization is indicated by its occurrence in the upper gut of mammals (mice and rats) $(28,106)$, reptiles (Burmese pythons, Python molurus Linnaeus) (107), and fish (goldfish, Carassius auratus Linnaeus) (108).

When administered as a drug to free-feeding mice or rats, OEA modifies meal patterns in a manner that is characteristic of a satiety signal, i.e., primarily by increasing post-meal intervals rather than reducing meal size (38). This effect is absent in mice lacking PPAR $\alpha$, to which OEA binds with high affinity (dissociation constant $\left[\mathrm{K}_{\mathrm{D}}\right] 40 \mathrm{nM}$ ), and is mimicked by synthetic PPAR $\alpha$ agonists, indicating that the nuclear receptor is both necessary and sufficient for OEA-induced hypophagia $(26,109)$. As mentioned above, OEA also engages GPR119 with micromolar potency to provoke the secretion of GLP1 (104). Genetic deletion of GPR119 eliminates GLP1 release elicited by exogenous OEA but does not affect the compound's ability to suppress food intake (35). Certain NAPE species, including some that do not generate OEA (e.g., $N$-palmitoyl-PE), are also able to reduce feeding in rats via a mechanism that appears to be centrally mediated (39). However, this effect only occurs after administration of high doses of NAPE, and doubts have been raised about its selectivity and physiological significance (110).

The finding that ingestion of dietary fat elevates OEA levels only in duodenal and jejunal mucosa - and not, for example, in the bloodstream or the brain (106) - suggests that this lipid-derived mediator might exert its anorexic effects through a mechanism similar to that of cholecystokinin, i.e., by paracrine activation of vagal afferents (100). This idea is supported by three findings: first, treatment with capsaicin, which deprives animals of peripheral vagal and nonvagal sensory fibers, abrogates the hypophagic response to OEA (28); second, systemic administration of OEA at dosages that do not allow the compound to enter the brain stimulates transcription of the early-immediate gene $c$-Fos (a marker of neuronal activation) in the NST (28); and third, surgical resection of the vagus nerve or anesthetic blockade of NST activity (with local microinjections of lidocaine) prevents several consequences of OEA administration, including enhancement of memory consolidation (111) and stimulation of dopamine release in the dorsal striatum (112). While these results suggest that OEA inhibits food intake by recruiting vagal sensory afferents (27), a recent report showing that subdiaphrag- matic vagotomy does not block OEA-evoked hypophagia has challenged this conclusion (113). These inconsistencies warrant further investigation.

In addition to its effects on the NST, administration of OEA stimulates $c$-Fos transcription in magnocellular neurons of the paraventricular and supraoptic nuclei of the hypothalamus (28), two structures that are intimately involved in feeding and energy homeostasis $(114,115)$. In the same neurons, OEA also enhances expression of the neuropeptide oxytocin, and injections of the oxytocin receptor antagonist L-368,899 into the cerebral ventricles impair the ability of systemic OEA injections to reduce food intake $(116,117)$. These findings are consistent with the idea that oxytocin neurotransmission in the CNS plays an obligatory role in the satietyinducing action of OEA (Figure 2). A recent report suggests that central histamine transmission may also be involved (118).

Along with the vagus nerve, the sympathetic nervous system also appears to contribute in important ways to OEA signaling. Surgical removal of the celiac-superior mesenteric ganglion, which supplies noradrenergic fibers to the intestine and other visceral organs, abolishes the anorexic actions caused by intraduodenal fat infusion in rats (119). The same surgical intervention also abrogates food-induced OEA mobilization in the rat jejunum, and this effect is mimicked by pharmacological inhibition of $\beta_{2}$-adrenergic receptors (120), which are highly expressed in gut serosa (121). Conversely, OEA administration corrects the feeding deficits produced by sympathetic denervation (i.e., increased meal frequency and decreased post-meal intervals) (120). A plausible interpretation of these findings is that sympathetic outflow to the small intestine enables fat-induced OEA satiety signaling, possibly by regulating the expression and/or post-translational regulation of enzymes in the pathway of OEA biosynthesis.

As seen with gut peptide hormones such as GLP1 $(122,123)$, continued exposure to a high-fat diet lowers OEA levels in the small intestine of rodents $(112,124,125)$. Does this effect influence OEA-mediated satiety signaling? We cannot answer this question yet, but recent work by Tellez and collaborators (112) provides data suggesting that dampened OEA availability in the gut may affect dopamine transmission in the dorsal striatum, a brain structure that links hedonic responses to habit learning (44). Using brain microdialysis, these researchers found that gastric infusions of fat increase striatal dopamine outflow in lean mice $(94,112)$. This response - which is prevented by pharmacological blockade of PPAR $\alpha$ or surgical resection of the vagus nerve - is absent in mice rendered obese by exposure to a high-fat diet, but could be reinstated by treating obese mice with exogenous OEA (112).

In summary, the available data indicate that OEA, generated by small-intestinal enterocytes during the digestion of fat-containing foods, causes satiety through a paracrine PPAR $\alpha$-mediated mechanism that requires the recruitment of afferent sensory fibers. This response also depends on the presence of an intact sympathetic nervous system - which may function to facilitate fat-induced OEA production in the gut - and engages oxytocin, histamine, and dopamine transmission in the CNS. The intriguing but as yet unexplained observation that prolonged exposure to dietary fat lowers small intestinal OEA levels $(124,125)$ raises questions about the mechanism regulating OEA signaling in the gut and the possible role it might play in overeating and obesity. 


\section{An integrated view}

Gut peptide hormones are differentially distributed along the longitudinal axis of the alimentary canal and serve complementary functions in the control of feeding behavior. For example, ghrelin released from specialized cells in the stomach stimulates food intake during fasting, whereas cholecystokinin and GLP1 secreted from enteroendocrine cells in the small intestine inhibit intake after feeding $(126,127)$. The evidence summarized in this article suggests that two chemically distinct classes of lipid-derived mediators glycerol esters and ethanolamides of LCFUs - may act in parallel and presumably in concert with peptide hormones to regulate the ingestion of fat-containing foods (Figure 2). As discussed above, select chemical components of dietary fat (e.g., mono- and diunsaturated fatty acids) trigger gustatory signals that drive feeding, in part by stimulating the accumulation of orexigenic endocannabinoid messengers in the jejunum. Vagal neurotransmission bridges the tasting of fat in the mouth to endocannabinoid mobilization in the gut. As fat-containing chyme travels through the small intestine, its triacylglycerol constituents undergo chemical changes that convert these diet-derived nutrients into signaling molecules: they are absorbed by enterocytes to be used as precursors for anorexic mediators such as OEA and are hydrolyzed in the gut lumen to form GPR119 agonists such as 2-OG. The sympathetic nervous system is necessary for at least one of these processes - the conversion of fat-derived oleic acid into OEA. The ability shown by both endocannabinoids $(128)$ and OEA $(22,129)$ to slow gastrointestinal transit likely contributes to the overall effects of these lipid mediators on food intake. Though still incomplete, this body of evidence allows us to conjecture that the ingestion of fat-rich foods initiates two temporally distinct events that require a coordinated interaction between the parasympathetic and sympathetic nervous systems: a cephalically driven induction of endocannabinoid activity in the gut, which acts as a "go" signal to maximize consumption of fat-rich foods, and a post-oral phase that includes the formation of OEA, which serves as a "stop" signal on feeding (Figure 2). This model underscores the close integration between gut and brain, likely a product of the co-evolution of these two metabolically expensive organs (130), and predicts that imbalances between opposing lipid-derived signaling systems and dysfunctions in their interactions with peptide hormones may lead to overweight and obesity.

\section{Acknowledgments}

The authors gratefully acknowledge support from U.S. National Institute on Drug Abuse grant K99/R00 DA034009 (to N.V. DiPatrizio) and U.S. National Institute of Diabetes and Digestive and Kidney Disorders grant DK073955 to (D. Piomelli).

Address correspondence to: Daniele Piomelli, 3216 Gillespie Neuroscience Research Facility, Irvine, California 92697, USA. Phone: 949.824.7080; E-mail: piomelli@uci.edu.

Nicholas V. DiPatrizio's present address is: Division of Biomedical Sciences, School of Medicine, University of California, Riverside, Riverside, California, USA.
1. Leonard WR, Snodgrass JJ, Robertson ML. Evolutionary perspectives on fat ingestion and metabolism in humans. In: Montmayeur JP, le Coutre J, eds. Fat Detection: Taste, Texture, and Post Ingestive Effects. Boca Raton, Florida, USA: CRC Press; 2010:Chapter 1.

2. Muskiet FAJ. Pathophysiology and evolutionary aspects of dietary fats and long-chain polyunsaturated fatty acids across the life cycle. In: Montmayeur JP, le Coutre J, eds. Fat Detection: Taste, Texture, and Post Ingestive Effects. Boca Raton, Florida, USA: CRC Press; 2010:Chapter 2.

3. Piomelli D, Astarita G, Rapaka R. A neuroscientist's guide to lipidomics. Nat Rev Neurosci. 2007;8(10):743-754

4. DiPatrizio NV, Piomelli D. The thrifty lipids: endocannabinoids and the neural control of energy conservation. Trends Neurosci. 2012;35(7):403-411.

5. Neel JV. Diabetes mellitus: a "thrifty" genotype rendered detrimental by "progress"? Am J Hum Genet.1962;(14):353-362.

6. Diamond J. The World Until Yesterday: What Can We Learn From Traditional Societies. New York, New York, USA: Penguin Press; 2012.

7. Zhang M, Gosnell BA, Kelley AE. Intake of high-fat food is selectively enhanced by mu opioid receptor stimulation within the nucleus accumbens. JPharmacol Exp Ther. 1998;285(2):908-914.

8. Baldo BA, Pratt WE, Kelley AE. Control of fat intake by striatal opioids. In: Montmayeur JP, le Coutre J, eds. Fat Detection: Taste, Texture, and Post Ingestive Effects. Boca Raton, Florida: CRC Press; 2010:Chapter 13.
9. Ogden CL, Carroll MD, Kit BK, Flegal KM. Prevalence of obesity in the United States, 2009-2010. NCHS data brief, no 82. Hyattsville, Maryland, USA: National Center for Health Statistics; 2012.

10. Williams KW, Elmquist JK. From neuroanatomy to behavior: central integration of peripheral signals regulating feeding behavior. Nat Neurosci. 2012;15(10):1350-1355.

11. Morganstern I, Chang GQ, Karatayev O, Leibowitz SF. Increased orexin melanin-concentrating hormone expression in the perifornical lateral hypothalamus of rats prone to overconsuming a fat-rich diet. Pharmacol Biochem Behav. 2010;96(4):413-422.

12. Piomelli D. More surprises lying ahead. The endocannabinoids keep us guessing. Neuropharmacology. 2014;76(pt B):228-234.

13. Mackie K. Distribution of cannabinoid receptors in the central and peripheral nervous system. Handb Exp Pharmacol. 2005;(168):299-325.

14. Bajzer M, et al. Cannabinoid receptor 1 (CB1) antagonism enhances glucose utilisation and activates brown adipose tissue in diet-induced obese mice. Diabetologia. 2011;54(12):3121-3131.

15. Ioannides-Demos LL, Piccenna L, McNeil JJ. Pharmacotherapies for obesity: past, current, and future therapies. JObes. 2011;2011:179674.

16. Berridge KC, Robinson TE. Parsing reward. Trends Neurosci. 2003;26(9):507-513.

17. Mahler SV, Smith KS, Berridge KC. Endocannabinoid hedonic hotspot for sensory pleasure: anandamide in nucleus accumbens shell enhances 'liking' of a sweet reward. Neuropsychopharmacology. 2007;32(11):2267-2278.
18. Quarta C, et al. CB(1) signaling in forebrain and sympathetic neurons is a key determinant of endocannabinoid actions on energy balance. Cell Metab. 2010;11(4):273-285.

19. Jung KM, et al. 2-arachidonoylglycerol signaling in forebrain regulates systemic energy metabolism. Cell Metab. 2012;15(3):299-310.

20. Kunos G, Tam J. The case for peripheral CB receptor blockade in the treatment of visceral obesity and its cardiometabolic complications. Br J Pharmacol. 2011;163(7):1423-1431.

21. Pertwee RG, Fernando SR, Nash JE, Coutts AA. Further evidence for the presence of cannabinoid $\mathrm{CB} 1$ receptors in guinea-pig small intestine. $\mathrm{Br} \mathrm{J}$ Pharmacol. 1996;118(8):2199-2205.

22. Aviello G, Romano B, Izzo AA. Cannabinoids and gastrointestinal motility: animal and human studies. Eur Rev Med Pharmacol Sci. 2008;12(suppl 1):81-93.

23. Alhouayek M, Muccioli GG. The endocannabinoid system in inflammatory bowel diseases: from pathophysiology to therapeutic opportunity. Trends Mol Med. 2012;18(10):615-625.

24. Gomez R, et al. A peripheral mechanism for CB1 cannabinoid receptor-dependent modulation of feeding. J Neurosci. 2002;22(21):9612-9617.

25. Storr MA, Sharkey KA. The endocannabinoid system and gut-brain signalling. Curr Opin Pharmacol. 2007;7(6):575-582.

26. Fu J, et al. Oleylethanolamide regulates feeding and body weight through activation of the nuclear receptor PPAR- $\alpha$. Nature. 2003;425(6953):90-93.

27. Piomelli $\mathrm{D}$. A fatty gut feeling. Trends Endocrinol Metab. 2013;24(7):332-341. 
28. Rodriguez de Fonseca F, et al. An anorexic lipid mediator regulated by feeding. Nature. 2001;414(6860):209-212.

29. Romano A, et al. High dietary fat intake influences the activation of specific hindbrain and hypothalamic nuclei by the satiety factor oleoylethanolamide. Physiol Behav. 2014;136:55-62.

30. Yang Y, Chen M, Georgeson KE, Harmon CM. Mechanism of oleoylethanolamide on fatty acid uptake in small intestine after food intake and body weight reduction. Am J Physiol Regul Integr Comp Physiol. 2007;292(1):R235-R241.

31. Guzman M, Lo Verme J, Fu J, Oveisi F, Blazquez C, Piomelli D. Oleoylethanolamide stimulates lipolysis by activating the nuclear receptor peroxisome proliferator-activated receptor alpha (PPAR- $\alpha$ ). JBiol Chem. 2004;279(27):27849-27854.

32. Suarez J, et al. Oleoylethanolamide enhances $\beta$-adrenergic-mediated thermogenesis and white-to-brown adipocyte phenotype in epididymal white adipose tissue in rat. Dis Model Mech. 2014;7(1):129-141.

33. Overton HA, et al. Deorphanization of a G protein-coupled receptor for oleoylethanolamide and its use in the discovery of small-molecule hypophagic agents. Cell Metab. 2006;3(3):167-175.

34. Lauffer LM, Iakoubov R, Brubaker PL. GPR119 is essential for oleoylethanolamide-induced glucagon-like peptide-1 secretion from the intestinal enteroendocrine L-cell. Diabetes. 2009;58(5):1058-1066.

35. Lan H, et al. GPR119 is required for physiological regulation of glucagon-like peptide-1 secretion but not for metabolic homeostasis. J Endocrinol. 2009;201(2):219-230.

36. Hansen KB, et al. 2-Oleoyl glycerol is a GPR119 agonist and signals GLP-1 release in humans. JClin Endocrinol Metab. 2011;96(9):E1409-E1417.

37. Schwartz GJ, et al. The lipid messenger OEA links dietary fat intake to satiety. Cell Metab. 2008;8(4):281-288.

38. Gaetani S, Oveisi F, Piomelli D. Modulation of meal pattern in the rat by the anorexic lipid mediator oleoylethanolamide. Neuropsychopharmacology. 2003;28(7):1311-1316.

39. Gillum MP, et al. N-acylphosphatidylethanolamine, a gut- derived circulating factor induced by fat ingestion, inhibits food intake. Cell. 2008;135(5):813-824.

40. Pollan M. The Omnivore's Dilemma: A Natural History of Four Meals. New York, New York, USA: Penguin Press; 2006.

41. Jiang $\mathrm{P}$, et al. Major taste loss in carnivorous mammals. Proc Natl Acad Sci U S A. 2012;109(13):4956-4961.

42. Price SA, Hopkins SS, Smith KK, Roth VL. Tempo of trophic evolution and its impact on mammalian diversification. Proc Natl Acad Sci U S A. 2012;109(18):7008-7012.

43. Ingram T, Harmon LJ, Shurin JB. Niche evolution, trophic structure, and species turnover in model food webs. Am Nat. 2009;174(1):56-67.

44. Rangel A. Regulation of dietary choice by the decision-making circuitry. Nat Neurosci. 2013;16(12):1717-1724.

45. Small DM. Flavor is in the brain. Physiol Behav. 2012;107(4):540-552.

46. Rolls ET. Neural representation of fat texture in the mouth. In: Montmayeur JP, le Coutre J, eds. Fat Detection: Taste, Texture, and Post Ingestive Effects. Boca Raton, Florida, USA; 2010:Chapter 8

47. Mattes RD. Oral detection of short-, medium-, and long-chain free fatty acids in humans. Chem Senses. 2009;34(2):145-150.

48. Fukuwatari T, et al. Role of gustation in the recognition of oleate and triolein in anosmic rats. Physiol Behav. 2003;78(4-5):579-583.

49. Takeda M, Sawano S, Imaizumi M, Fushiki T. Preference for corn oil in olfactory-blocked mice in the conditioned place preference test and the twobottle choice test. LifSci. 2001;69(7):847-854

50. Breslin PA, Spector AC. Mammalian taste perception. Curr Biol. 2008;18(4):R148-R155.

51. Hamilton RB, Norgren R. Central projections of gustatory nerves in the rat. J Comp Neurol. 1984;222(4):560-577.

52. Grill HJ, Hayes MR. Hindbrain neurons as an essential hub in the neuroanatomically distributed control of energy balance. Cell Metab. 2012;16(3):296-309.

53. Carter ME, Soden ME, Zweifel LS, Palmiter RD. Genetic identification of a neural circuit that suppresses appetite. Nature. 2013;503(7474):111-114

54. DiPatrizio NV, Simansky KJ. Activating parabrachial cannabinoid CB1 receptors selectively stimulates feeding of palatable foods in rats. J Neurosci. 2008;28(39):9702-9709.

55. Stratford JM, Curtis KS, Contreras RJ. Chorda tympani nerve transection alters linoleic acid taste discrimination by male and female rats. Physiol Behav. 2006;89(3):311-319.

56. Pittman D, Crawley ME, Corbin CH, Smith KR Chorda tympani nerve transection impairs the gustatory detection of free fatty acids in male and female rats. Brain Res. 2007;1151:74-83.

57. Gaillard D, et al. The gustatory pathway is involved in CD36-mediated orosensory perception of long-chain fatty acids in the mouse. FASEB J. 2008;22(5):1458-1468.

58. Treesukosol Y, Blonde GD, Jiang E, Gonzalez D, Smith JC, Spector AC. Necessity of the glossopharyngeal nerve in the maintenance of normal intake and ingestive bout size of corn oil by rats. Am J Physiol Regul Integr Comp Physiol. 2010;299(4):R1050-R1058.

59. Foo H, Norgren R. Concentration and state dependent reductions in corn oil intakes after glossopharyngeal nerve transections in rats. Physiol Behav. 2014;(128):166-171.

60. Liang NC, Hajnal A, Norgren R. Sham feeding corn oil increases accumbens dopamine in the rat. Am J Physiol Regul Integr Comp Physiol. 2006;291(5):R1236-R1239.

61. Adachi SI, et al. Increased levels of extracellular dopamine in the nucleus accumbens and amygdala of rats by ingesting a low concentration of a long-chain Fatty Acid. Biosci Biotechnol Biochem. 2013;77(11):2175-2180.

62. Mattes RD. Accumulating evidence supports a taste component for free fatty acids in humans. Physiol Behav. 2011;104(4):624-631.

63. DiPatrizio NV. Is fat taste ready for primetime? Physiol Behav. 2014;136C:145-154.

64. Pepino MY, Love-Gregory L, Klein S, Abumrad NA. The fatty acid translocase gene CD36 and lingual lipase influence oral sensitivity to fat in obese subjects. JLipid Res. 2012;53(3):561-566.

65 . Voigt $\mathrm{N}$, et al. The role of lipolysis in human orosensory fat perception. J Lipid Res. 2014;55(5):870-882.

66. Kawai T, Fushiki T. Importance of lipolysis in ora cavity for orosensory detection of fat. Am J Physiol Regul Integr Comp Physiol. 2003;285(2):R447-R454.

67. Hamosh M, Scow RO. Lingual lipase and its role in the digestion of dietary lipid. J Clin Invest. 1973;52(1):88-95.

68. Hamosh M, Burns WA. Lipolytic activity of human lingual glands (Ebner). Lab Invest. 1977;37(6):603-608.

69. Laugerette F, et al. CD36 involvement in orosensory detection of dietary lipids, spontaneous fat preference, and digestive secretions. J Clin Invest. 2005;115(11):3177-3184.

70. Sclafani A, Ackroff K, Abumrad NA. CD36 gene deletion reduces fat preference and intake but not post-oral fat conditioning in mice. Am JPhysiol Regul Integr Comp Physiol. 2007;293(5):R1823-R1832.

71. Cartoni $\mathrm{C}$, et al. Taste preference for fatty acids is mediated by GPR40 and GPR120. J Neurosci. 2010;30(25):8376-8382.

72. Liu P, Shah BP, Croasdell S, Gilbertson TA. Transient receptor potential channel type M5 is essential for fat taste. J Neurosci. 2011;31(23):8634-8642.

73. El-Yassimi A, Hichami A, Besnard P, Khan NA Linoleic acid induces calcium signaling, Src kinase phosphorylation, and neurotransmitter release in mouse CD36-positive gustatory cells. J Biol Chem. 2008;283(19):12949-12959.

74. Chevrot M, et al. Obesity interferes with the orosensory detection of long-chain fatty acids in humans. Am J Clin Nutr. 2014;99(5):975-983.

75. Feng P, Zheng J, Rossiter SJ, Wang D, Zhao H. Massive losses of taste receptor genes in toothed and baleen whales. Genome Biol Evol. 2014;6(6):1254-1265

76. Zhao H, Yang JR, Xu H, Zhang J. Pseudogenization of the umami taste receptor gene Tas1r1 in the giant panda coincided with its dietary switch to bamboo. Mol Biol Evol. 2010;27(12):2669-2673.

77. Greenberg D, Smith GP. The controls of fat intake. Psychosom Med.1996;58(6):559-569.

78. Castro DC, Berridge KC. Advances in the neurobiological bases for food 'liking' versus 'wanting'. Physiol Behav. 2014;136:22-30.

79. Volkow ND1, Wang GJ, Fowler JS, Tomasi D, Baler R. Food and drug reward: overlapping circuits in human obesity and addiction. Curr Top Behav Neurosci. 2012;11:1-24.

80. DiLeone RJ, Taylor JR, Picciotto MR. The drive to eat: comparisons and distinctions between mechanisms of food reward and drug addiction. Nat Neurosci. 2012;15(10):1330-1335.

81. Kenny PJ. Common cellular and molecular mechanisms in obesity and drug addiction. Nat Rev Neurosci. 2011;12(11):638-651.

82. Avena NM, Bocarsly ME, Hoebel BG. Animal models of sugar and fat bingeing: relationship to food addiction and increased body weight. Methods Mol Biol. 2012;829:351-365.

83. DiPatrizio NV, Astarita G, Schwartz G, Li X, Piomelli D. Endocannabinoid signal in the gut controls dietary fat intake. Proc Natl Acad Sci US A. 2011;108(31):12904-12908.

84. DiPatrizio NV, Joslin A, Jung KM, Piomelli D. 
Endocannabinoid signaling in the gut mediates preference for dietary unsaturated fats. FASEB $J$. 2013;27(6):2513-2520.

85. Berthoud HR. The vagus nerve, food intake and obesity. Regul Pept. 2008;149(1-3):15-25.

86. Izzo AA, et al. Peripheral endocannabinoid dysregulation in obesity: relation to intestinal motility and energy processing induced by food deprivation and re-feeding. Br J Pharmacol. 2009;158(2):451-461

87. Vianna CR, et al. Cannabinoid receptor 1 in the vagus nerve is dispensable for body weight homeostasis but required for normal gastrointestinal motility. JNeurosci. 2012;32(30):10331-10337.

88. Senin LL, et al. The gastric CB1 receptor modulates ghrelin production through the mTOR pathway to regulate food intake. PLoS One. 2013;8(11):e80339.

89. Sykaras AG, Demenis C, Case RM, McLaughlin JT, Smith CP. Duodenal enteroendocrine I-cells contain mRNA transcripts encoding key endocannabinoid and fatty acid receptors. PLoS One. 2012;7(8):e42373.

90. Izzo AA, Sharkey KA. Cannabinoids and the gut: New developments and emerging concepts. Pharmacol Ther. 2010;126(1):21-38.

91. Hons IM, et al. Plasticity of mouse enteric synapses mediated through endocannabinoid and purinergic signaling. Neurogastroenterol Motil. 2012;24(3):e113-e124.

92. Ji Y, et al. Activation of rat intestinal mucosal mast cells by fat absorption. Am J Physiol Gastrointest Liver Physiol. 2012;302(11):G1292-G1300.

93. Bellocchio L, et al. Activation of the sympathetic nervous system mediates hypophagic and anxiety-like effects of CB1 receptor blockade. Proc Natl Acad Sci U S A. 2013;110(12):4786-4791.

94. Ferreira JG, Tellez LA, Ren X, Yeckel CW, de Araujo IE. Regulation of fat intake in the absence of flavour signalling. J Physiol. 2012;590(pt 4):953-972.

95. Ackroff K, Sclafani A. Oral and Postoral Determinants of dietary fat intake. In: Montmayeur JP, le Coutre J, eds. Fat Detection: Taste, Texture, and Post Ingestive Effects. Boca Raton, Florida, USA; 2010:Chapter 12.

96. Schwartz GJ. Gut fat sensing in the negative feedback control of energy balance-recent advances. Physiol Behav. 2011;104(4):621-623.

97. Ryan AT, et al. Effects of intraduodenal lipid and protein on gut motility and hormone release, glycemia, appetite, and energy intake in lean men. Am J Clin Nutr. 2013;98(2):300-311.

98. Yox DP, Stokesberry H, Ritter RC. Vagotomy attenuates suppression of sham feeding induced by intestinal nutrients. Am J Physiol. 1991;260(3 pt 2):R503-R508.

99. Tamura CS, Ritter RC. Intestinal capsaicin transiently attenuates suppression of sham feeding by oleate. Am J Physiol. 1994;267(2 pt 2):R561-R568.
100.Smith GP, Jerome C, Cushin BJ, Eterno R, Simansky KJ. Abdominal vagotomy blocks the satiety effect of cholecystokinin in the rat. Science. 1981;213(4511):1036-1037.

101.Yox DP, Brenner L, Ritter RC. CCK-receptor antagonists attenuate suppression of sham feeding by intestinal nutrients. Am J Physiol. 1992;262(4 pt 2):R554-R561.

102. Reimann F, Tolhurst G, Gribble FM. G-protein-coupled receptors in intestinal chemosensation. Cell Metab. 2012;15(4):421-431.

103. Shah BP, Liu P, Yu T, Hansen DR, Gilbertson TA. TRPM5 is critical for linoleic acid-induced CCK secretion from the enteroendocrine cell line, STC-1. Am J Physiol Cell Physiol. 2012;302(1):C210-C219.

104. Hansen HS, Rosenkilde MM, Holst JJ, Schwartz TW. GPR119 as a fat sensor. Trends Pharmacol Sci. 2012;33(7):374-381.

105. Martin C, et al. Lipid-mediated release of GLP-1 by mouse taste buds from circumvallate papillae: putative involvement of GPR120 and impact on taste sensitivity. J Lipid Res. 2012;53(11):2256-2265.

106. Fu J, et al. Food intake regulates oleoylethanolamide formation and degradation in the proximal small intestine. J Biol Chem. 2007;282(2):1518-1528.

107. Astarita G, et al. Postprandial increase of oleoylethanolamide mobilization in small intestine of the Burmese python (Python molurus). Am J Physiol Regul Integr Comp Physiol. 2006;290(5):R1407-R1412.

108. Tinoco AB, Armirotti A, Isorna E, Delgado MJ, Piomelli D, de Pedro N. Role of oleoylethanolamide as a feeding regulator in goldfish.J Exp Biol. 2014;217(pt 15):2761-2769.

109. Astarita G, et al. Pharmacological characterization of hydrolysis-resistant analogs of oleoylethanolamide with potent anorexiant properties. JPharmacol Exp Ther. 2006;318(2):563-570.

110.Wellner N, Diep TA, Janfelt C, Hansen HS. $\mathrm{N}$-acylation of phosphatidylethanolamine and its biological functions in mammals. Biochim Biophys Acta. 2013;1831(3):652-662.

111. Campolongo P, et al. Fat-induced satiety factor oleoylethanolamide enhances memory consolidation. Proc Natl Acad Sci U S A. 2009;106(19):8027-8031.

112. Tellez LA, et al. A gut lipid messenger links excess dietary fat to dopamine deficiency. Science. 2013;341(6147):800-802.

113. Azari EK, et al. Vagal afferents are not necessary for the satiety effect of the gut lipid messenger oleoylethanolamide (OEA). Am J Physiol Regul Integr Comp Physiol. 2014;307(2):R167-R178.

114. Hazell GG, et al. G protein-coupled receptors in the hypothalamic paraventricular and supraoptic nuclei - serpentine gateways to neuroendocrine homeostasis. Front Neuroendocrinol. 2012;33(1):45-66.
115. Sabatier N, Leng G, Menzies J. Oxytocin, feeding, and satiety. Front Endocrinol (Lausanne). 2013;4:35.

116. Gaetani S, et al. The fat-induced satiety factor oleoylethanolamide suppresses feeding through central release of oxytocin. J Neurosci. 2010;30(24):8096-8101.

117. Romano A, et al. Hindbrain noradrenergic input to the hypothalamic PVN mediates the activation of oxytocinergic neurons induced by the satiety factor oleoylethanolamide. Am J Physiol Endocrinol Metab. 2013;305(10):E1266-E1273.

118. Provensi G, et al. Satiety factor oleoylethanolamide recruits the brain histaminergic system to inhibit food intake. Proc Natl Acad Sci U S A. 2014;111(31):11527-11532.

119. Sclafani A, Ackroff K, Schwartz GJ. Selective effects of vagal deafferentation and celiac-superior mesenteric ganglionectomy on the reinforcing and satiating action of intestinal nutrients. Physiol Behav. 2003;78(2):285-294.

120. Fu J, et al. Sympathetic activity controls fatinduced oleoylethanolamide signaling in small intestine. J Neurosci. 2011;31(15):5730-5736.

121. Nasser Y, Ho W, Sharkey KA. Distribution of adrenergic receptors in the enteric nervous system of the guinea pig, mouse, and rat. JComp Neurol. 2006;495(5):529-553.

122. Williams DL, et al. Maintenance on a high-fat diet impairs the anorexic response to glucagonlike-peptide-1 receptor activation. Physiol Behav. 2011;103(5):557-564.

123. Anini Y, Brubaker PL. Role of leptin in the regulation of glucagon-like peptide-1 secretion. Diabetes. 2003;52(2):252-259.

124. Artmann A, et al. Influence of dietary fatty acids on endocannabinoid and $\mathrm{N}$-acylethanolamine levels in rat brain, liver and small intestine. Biochim Biophys Acta. 2008;1781(4):200-212.

125. Diep TA, et al. Dietary fat decreases intestinal levels of the anorectic lipids through a fat sensor. FASEB J. 2011;25(2):765-774.

126.Sam AH, Troke RC, Tan TM, Bewick GA. The role of the gut/brain axis in modulating food intake. Neuropharmacology. 2012;63(1):46-56.

127. Murphy KG, Bloom SR. Gut hormones and the regulation of energy homeostasis. Nature. 2006;444(7121):854-859.

128. Capasso R, Izzo AA. Gastrointestinal regulation of food intake: general aspects and focus on anandamide and oleoylethanolamide. J Neuroendocrinol. 2008;20(suppl 1):39-46.

129. Cluny NL, Keenan CM, Lutz B, Piomelli D, Sharkey KA. The identification of peroxisome proliferator-activated receptor alpha-independent effects of oleoylethanolamide on intestinal transit in mice. Neurogastroenterol Motil. 2009;21(4):420-429.

130. Aiello LC, Wheeler P. The expensive-tissue hypothesis. Curr Anthropol. 1995;36(2):199-221. 